\title{
Phosphorus sorption and buffering mechanisms in suspended sediments from the Yangtze Estuary and Hangzhou Bay, China
}

\author{
M. Li ${ }^{1}$, M. J. Whelan ${ }^{2}$, G. Q. Wang ${ }^{3}$, and S. M. White ${ }^{2}$ \\ ${ }^{1}$ College of Environmental Science and Engineering, Beijing Forestry University, Beijing 100083, China \\ ${ }^{2}$ School of Applied Sciences, Cranfield University, Bedfordshire, MK43 0AL, UK \\ ${ }^{3}$ State Key Laboratory of Hydroscience and Engineering, Tsinghua University, Beijing 100084, China
}

Correspondence to: M. Li (liminbjfu@126.com)

Received: 19 October 2012 - Published in Biogeosciences Discuss.: 10 December 2012

Revised: 3 March 2013 - Accepted: 20 April 2013 - Published: 17 May 2013

\begin{abstract}
The adsorption isotherm and the mechanism of the buffering effect are important controls on phosphorus (P) behaviors in estuaries and are important for estimating phosphate concentrations in aquatic environments. In this paper, we derive phosphate adsorption isotherms in order to investigate sediment adsorption and buffering capacity for phosphorus discharged from sewage outfalls in the Yangtze Estuary and Hangzhou Bay near Shanghai, China. Experiments were also carried out at different temperatures in order to explore the buffering effects for phosphate. The results show that $\mathrm{P}$ sorption in sediments with low fine particle fractions was best described using exponential equations. Some $\mathrm{P}$ interactions between water and sediment may be caused by the precipitation of $\mathrm{CaHPO}_{4}$ from $\mathrm{Ca}^{2+}$ and $\mathrm{HPO}_{4}^{2-}$ when the phosphate concentration in the liquid phase is high. Results from the buffering experiments suggest that the Zero Equilibrium Phosphate Concentrations $\left(\mathrm{EPC}_{0}\right)$ vary from $0.014 \mathrm{mg} \mathrm{L}^{-1}$ to $0.061 \mathrm{mg} \mathrm{L}^{-1}$, which are consistent with measured phosphate concentrations in water samples collected at the same time as sediment sampling. Values of $\mathrm{EPC}_{0}$ and linear sorption coefficients $(K)$ in sediments with high fine particle and organic matter contents are relatively high, which implies that they have high buffering capacity. Both $\mathrm{EPC}_{0}$ and $K$ increase with increasing temperature, indicating a higher $\mathrm{P}$ buffering capacity at high temperatures.
\end{abstract}

\section{Introduction}

Phosphorus $(\mathrm{P})$ is a major limiting nutrient in many surface waters and is often responsible for triggering eutrophication and toxic algal blooms (Kawasaki et al., 2010; Pratt and Shilton, 2009). In estuarine and coastal waters, P exchange at seawater-sediment interfaces can exert significant influence on $\mathrm{P}$ availability and it is, therefore, important to understand and describe this process well. Three equations (Langmuir, Freundlich and Temkin) are commonly used to describe sorption equilibria in water-sediment systems.

$\mathrm{P}$ can rapidly react with particle surfaces in natural systems (Froelich, 1988; Borggaard et al., 2004). The physicochemical reactions of $\mathrm{P}$ between overlying water and sediment in natural systems include adsorption/desorption and precipitation/dissolution reactions, which together, regulate soluble $\mathrm{P}$ concentrations in natural rivers, streams and estuaries (Wauchope and McDowell, 1984; Price et al., 2010). This phenomenon is known as the "phosphate buffer mechanism" (Richardson, 1985), which assumes that sediment, whether benthic or suspended, maintain dissolved reactive phosphate concentrations at some near-constant value regardless of biological removal and exogenic inputs (Froelich, 1988). $\mathrm{P}$ is sorbed onto particles in rivers, and then carried into estuaries. In estuaries, where freshwater and seawater mix, phosphorus is desorbed from particles to augment dissolved phosphate, especially in anoxic, saline sediment (Conley et al., 1995). This buffering effect is partly attributed to the adsorption of $\mathrm{P}$ onto metal oxide surfaces. Particulate phosphorus associated with iron and aluminium oxides often decreases with increasing salinity, suggesting that dissolved 
Table 1. Description of different sediment and water samples.

\begin{tabular}{|c|c|c|c|c|c|c|c|}
\hline \multirow{2}{*}{ Site } & & \multicolumn{2}{|c|}{$\mathrm{DIP}^{*}\left(\mathrm{mg} \mathrm{L}^{-1}\right)$} & \multirow{2}{*}{$\mathrm{OM}^{* *}(\%)$} & \multicolumn{3}{|c|}{ Particle size composition ( $\%$ total volume) } \\
\hline & & Range & Mean & & $\begin{array}{c}0.25- \\
0.074 \mathrm{~mm}\end{array}$ & $\begin{array}{c}0.074- \\
0.005 \mathrm{~mm}\end{array}$ & $<0.005 \mathrm{~mm}$ \\
\hline \multirow{3}{*}{ Xinghuo } & $\mathrm{A}$ & & & 0.66 & 0 & 73 & 27 \\
\hline & $\mathrm{B}$ & $0.040-0.077$ & 0.048 & 0.02 & 0 & 95 & 5 \\
\hline & $\mathrm{F}$ & & & 0.25 & 58 & 36 & 6 \\
\hline Zhuyuan & $\mathrm{Z} 4$ & $0.004-0.076$ & 0.042 & 0.82 & 0 & 72 & 28 \\
\hline Bailonggang & W4 & $0.028-0.116$ & 0.049 & 0.77 & 0 & 80 & 20 \\
\hline
\end{tabular}

* DIP: Dissolved inorganic phosphate of the water samples; ** OM: Organic matter content of the sediment samples.

phosphate concentrations might be partly buffered by desorption from aluminium and iron oxide phases (Conley et al., 1995; Schippers et al., 2006).

The Yangtze Estuary in eastern China frequently experiences eutrophication problems which are often manifested as red tides and fish kills (Xiang, 2011). Phosphate, primarily from treated wastewater outfalls is believed to be the principal driver for these phenomena ( $\mathrm{Li}$ et al., 2004). High sediment loads are transported to the estuary by the Yangtze River every year (Liu et al., 2008). This causes the aggregation of sediment particles in the Yangtze Estuary and Hangzhou Bay, which in turn maintains the availability of dissolved-phase $\mathrm{P}$ via adsorption and/or desorption reactions.

In this paper, $\mathrm{P}$ sorption behavior in sediments collected close to wastewater outfalls in the Yangtze Estuary and Hangzhou Bay was investigated. The suitability of three commonly used sorption isotherm models was evaluated, along with the potential for predicting the dissolved reactive phosphate concentration by buffering experiments.

\section{Materials and methods}

\subsection{Sampling}

Surface sediment samples $(0-2 \mathrm{~cm})$ were collected from effluent outfall areas in the Yangtze Estuary and Hangzhou Bay using a CN-11 sediment sampler (Beijing Zhuochuan Electronic Technology Co., Ltd.) (Li et al., 2004). The locations of the three outfalls and the five sediment sampling sites are shown in Fig. 1. Two sampling sites (Z4 and W4) are located around the Zhuyuan and Bailonggang outfall areas in the Yangtze Estuary. The distances between sampling sites and the outfalls are all approximately $0.5 \mathrm{~km}$. These two outfalls discharge effluent from municipal wastewater treatment plants with chemical enhanced primary treatment processes. The other three sampling sites (A, B and F) are located in the area around the Xinghuo outfall, which discharges effluent from an industrial park wastewater treatment plant, in Hangzhou Bay. The distance between sampling site B and the outfall is also $0.5 \mathrm{~km}$. The distance between sampling site
$\mathrm{B}$ and $\mathrm{A}$ is $1 \mathrm{~km}$ and that between $\mathrm{B}$ and $\mathrm{F}$ is $3 \mathrm{~km}$. Three sediments were obtained at each sampling site and stored together in one air-sealed plastic bag at $4{ }^{\circ} \mathrm{C}$ before being transported back to the laboratory (within $12 \mathrm{~h}$ ). All sediments were subsequently air dried, homogenized and passed through a $0.15 \mathrm{~mm}$ sieve and then stored in wide-mouthed amber glass jars in a dry, ventilated place.

A description and characterization of all samples is shown in Table 1. The organic matter (OM) content in the sediment was determined by the potassium bichromate-dilution heat colorimetric method (Bao and Jiang, 1999). The particle size distributions of the sediment samples on a weight basis were determined by the pipette method (Beuselinck et al., 1998). Water samples were also collected around each sediment sampling site at the same time, which were analysed for dissolved inorganic phosphate (DIP) concentration (Table 1). Triplicate samples were used for all determinations and results are presented as means of three replicate analyses. Standard errors (not shown) were always less than $\pm 5 \%$ of the mean value.

\subsection{Isothermal adsorption experiments}

Phosphate sorption isotherms were determined experimentally. Aliquots of dry, sieved and ground sediment $(0.5 \mathrm{~g} \pm 0.0001 \mathrm{~g})$ were placed in $250 \mathrm{~mL}$ glass conical flasks. Then, artificial sea water $(100 \mathrm{~mL}$, salinity 5$)$, prepared according to the method proposed by Liu et al. (1982), with $\mathrm{P}$ were added to each flask. This solution was spiked with $\mathrm{KH}_{2} \mathrm{PO}_{4}$ to give one of seven nominal phosphorus concentrations $\left(0.5,2,4,8,12,16\right.$ and $\left.20 \mathrm{mg} \mathrm{PL}^{-1}\right)$. Blank flasks containing no sediment were also prepared. Initial $\mathrm{P}$ concentrations in each incubation solution were determined by molybdate colorimetry (Kara et al., 1997). pH, including the blank experiments, was adjusted to a value of 8 using diluted $\mathrm{KOH}$ or $\mathrm{HNO}_{3}$ in order to minimize $\mathrm{pH}$ variations due to the different amounts of $\mathrm{KH}_{2} \mathrm{PO}_{4}$ added. The conical flasks were sealed and shaken continuously at $200 \mathrm{rpm}$ and $25 \pm 1^{\circ} \mathrm{C}$ for $24 \mathrm{~h}$ and then centrifuged at $3000 \mathrm{rpm}$ (maximum relative centrifugal force: $1207 \mathrm{~g}$ ) for $10 \mathrm{~min}$. Phosphate concentrations in the supernatant after centrifugation 
Table 2. Langmuir, Freundlich, Temkin isotherm equations and constants for adsorption of phosphate by different sediments.

\begin{tabular}{|c|c|c|c|c|c|}
\hline \multicolumn{6}{|c|}{ Langmuir equation } \\
\hline Sample & $\frac{c}{\Gamma}=\frac{c}{\Gamma_{\infty}}+\frac{1}{\Gamma_{\infty} b}$ & $\Gamma_{\infty}\left(\mu \mathrm{g} \mathrm{Pg}^{-1}\right)$ & $b\left(\mathrm{~L} \mathrm{mg}^{-1}\right)$ & $r$ & $S$ \\
\hline A & $\frac{c}{\Gamma}=0.0042 c+0.0098$ & 238.09 & 0.428 & 0.996 & 12.632 \\
\hline B & $\frac{c}{\Gamma}=0.0062 c+0.0969$ & 161.29 & 0.064 & 0.463 & 63.425 \\
\hline $\mathrm{F}$ & $\frac{c}{\Gamma}=0.0101 c+0.0557$ & 99.01 & 0.181 & 0.711 & 35.791 \\
\hline $\mathrm{Z} 4$ & $\frac{c}{\Gamma}=0.0027 c+0.0066$ & 370.37 & 0.409 & 0.992 & 12.885 \\
\hline W4 & $\frac{c}{\Gamma}=0.0028 c+0.0081$ & 357.14 & 0.346 & 0.997 & 13.461 \\
\hline \multicolumn{6}{|c|}{ Freundlich equation } \\
\hline sample & $\lg \Gamma=\frac{1}{n} \lg c+\lg k$ & $K$ & $n$ & $r$ & $S$ \\
\hline A & $\lg \Gamma=0.3896 \lg c+1.8721$ & 74.49 & 2.567 & 0.995 & 11.075 \\
\hline B & $\lg \Gamma=0.5067 \lg c+1.2752$ & 18.845 & 1.974 & 0.801 & 64.842 \\
\hline $\mathrm{F}$ & $\lg \Gamma=0.2282 \lg c+1.5456$ & 35.124 & 4.382 & 0.655 & 35.171 \\
\hline $\mathrm{Z} 4$ & $\lg \Gamma=0.7297 \lg c+1.78$ & 60.256 & 1.37 & 0.968 & 71.921 \\
\hline W4 & $\lg \Gamma=0.4974 \lg c+1.9392$ & 86.936 & 2.01 & 0.974 & 30.954 \\
\hline \multicolumn{6}{|c|}{ Temkin equation } \\
\hline Sample & $\Gamma=\frac{\Gamma_{\infty} R T}{\beta Q_{0}} \times \ln \left(C_{0} c\right)$ & & & $r$ & $S$ \\
\hline A & $\Gamma=43.38 \ln c+84.588$ & & & 0.987 & 11.433 \\
\hline B & $\Gamma=32.103 \ln c+10.449$ & & & 0.585 & 64.829 \\
\hline $\mathrm{F}$ & $\Gamma=15.316 \ln c+33.008$ & & & 0.556 & 35.094 \\
\hline $\mathrm{Z4}$ & $\Gamma=56.739 \ln c+147.12$ & & & 0.988 & 22.037 \\
\hline W4 & $\Gamma=68.553 \ln c+113.41$ & & & 0.994 & 11.648 \\
\hline
\end{tabular}

$\Gamma$ : equilibrium $\mathrm{P}$ adsorption amount; $c$ : equilibrium $\mathrm{P}$ concentration in liquid phase; $\Gamma_{\infty}$ : maximum adsorption amount; $b$ : adsorption equilibrium constant; $r$ : correlation coefficient; $S$ : standard deviation; $K$ : empirical constant; $n$ : empirical constant.

were determined and assumed to be the final $\mathrm{P}$ concentration. The difference between initial and final $\mathrm{P}$ concentrations was used to calculate phosphate adsorption capacity. Triplicate experiments were conducted for all samples and results were presented as means of three parallel determinations. Standard errors are not shown here since they were always less than $\pm 5 \%$ of the mean value.

\subsection{Phosphate buffer experiments}

Phosphate buffering experiments, similar to the adsorption experiments described above, were carried out, except using very low initial $P$ concentrations of $0,0.04,0.08,0.12,0.2$, $0.3,0.4$ and $0.5 \mathrm{mg} \mathrm{PL}^{-1}$, which represent the range of concentrations commonly encountered under natural conditions. The experiments were conducted at three constant temperatures of $12{ }^{\circ} \mathrm{C}, 22^{\circ} \mathrm{C}$ and $32^{\circ} \mathrm{C}$, respectively, to investigate the influence of temperature on buffering capacity.

$\left[P_{D}\right]_{\text {initial }}$ represents the initial liquid-phase phosphate concentration before shaking, while $\left[\mathrm{P}_{\mathrm{D}}\right]_{\text {final }}$ represents the equilibrium liquid-phase phosphate concentration. The difference between $\left[\mathrm{P}_{\mathrm{D}}\right]_{\text {initial }}$ and $\left[\mathrm{P}_{\mathrm{D}}\right]_{\text {final }}$ is expressed as $\Delta \mathrm{P}_{\mathrm{D}}$. $\mathrm{P}$ is absorbed by sediments when $\Delta \mathrm{P}_{\mathrm{D}}$ is positive and desorbed from sediments when $\Delta P_{D}$ is negative. $\Delta P_{S}$ represents the $P$ adsorbed or desorbed per unit mass of sediment.

\section{Results and discussion}

\subsection{Adsorption isotherm models}

The adsorption isotherms of five sediment samples are shown in Fig. 2a. Langmuir, Freundlich and Temkin adsorption isotherm equations were well known and used in many previous studies (Borggaard et al., 2005). These three isotherm equations were obtained by least squares fitting to experimental sorption data. The isotherm equations, derived constants $(\Gamma \infty, b, K$ and $n)$, correlation coefficients $(r)$ and standard deviation $(S)$ are shown in Table 2. The theoretical Langmuir and exponential isotherms are also plotted in Fig. 2a. Samples A, Z4 and W4 were all well described using the Langmuir adsorption isotherm with similar parameters. These curves are clearly distinct from the best-fit sorption isotherms obtained for samples B and F which were best described using exponential isotherms.

It is clear from Table 2 that the $\mathrm{P}$-adsorption data for samples A, Z4 and W4 can be well described using all three isotherm models $(r \geq 0.968)$. The best suitable isotherm model for these three sediments was selected on the basis of the highest mean correlation coefficients $(r)$ and lowest mean standard deviation $(S)$ values for the three samples. Overall, the Langmuir equation was considered to give the best fit for these samples. 


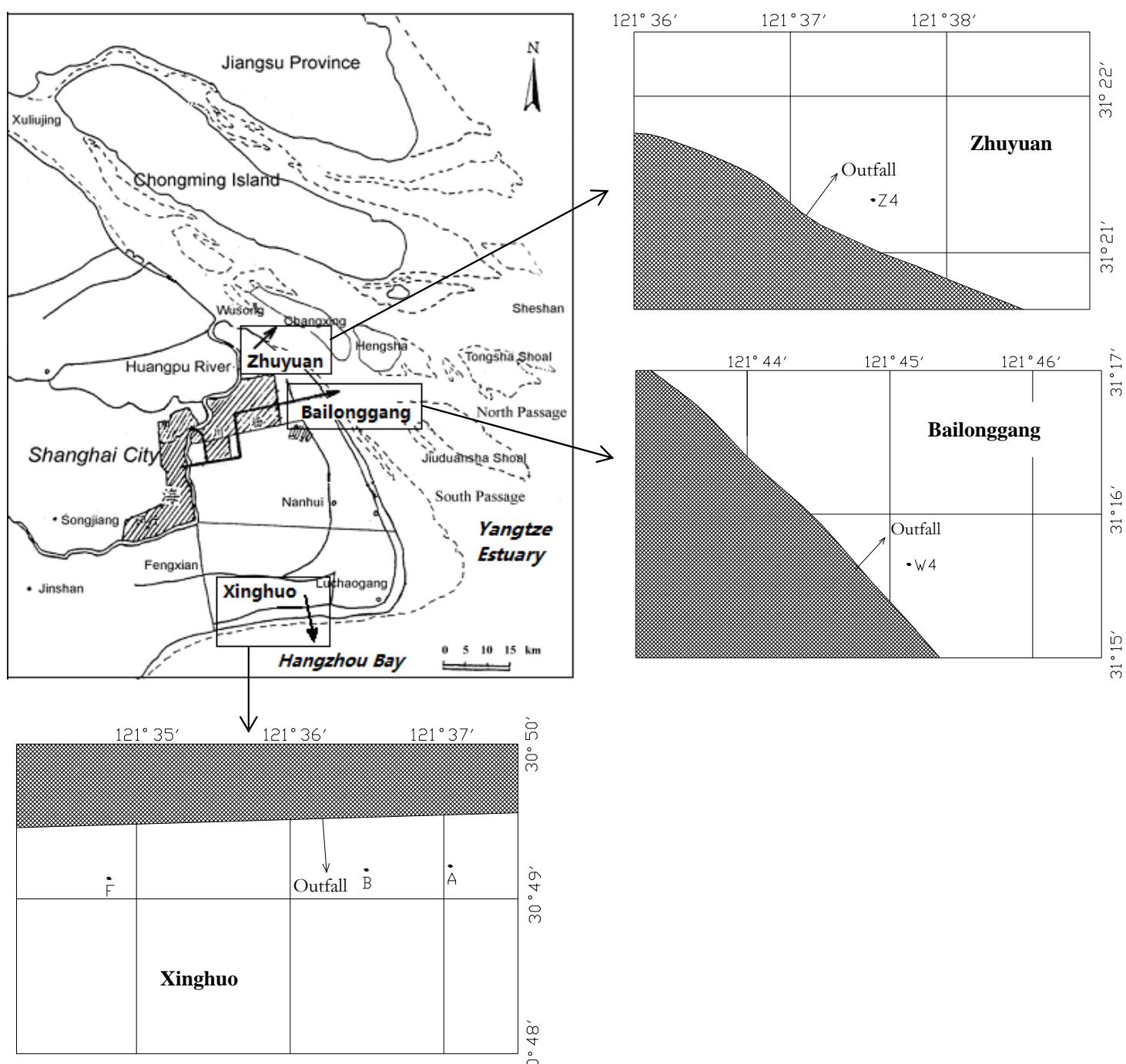

Fig. 1. Sketch map of sediment sampling site locations for the Zhuyuan, Bailonggang and Xinghuo outfalls.

Sorption data from samples B and $\mathrm{F}$ were not well described by any of the isotherm equations $(0.463<r<0.801)$. Visual inspection of the sorption data for these samples (Fig. 2a) suggests that an exponential model may be more appropriate for describing sorption in these samples. Least squares fitting of exponential equations to data from samples $\mathrm{B}$ and $\mathrm{F}$ yielded the following results:

$$
\begin{aligned}
& \mathrm{B}: \Gamma=16.464 \exp (0.1125 c) \quad r=0.930 \\
& \mathrm{~F}: \Gamma=30.65 \exp (0.0588 c) \quad r=0.844 .
\end{aligned}
$$

Equilibrium $\mathrm{P}$-adsorption capacity versus initial liquidphase phosphate concentrations for samples $\mathrm{B}$ and $\mathrm{F}$ are shown in Fig. 2b. When the initial P concentrations of the solution are lower than $12 \mathrm{mg} \mathrm{L}^{-1}$, the $\mathrm{P}$-adsorption capacities of both samples are relatively low and remain approximately constant with increased phosphate concentration. When the initial phosphate concentrations are higher than $12 \mathrm{mg} \mathrm{L}^{-1}$, on the other hand, the adsorption capacities increase rapidly. This suggests that precipitation reactions may occur during the adsorption process at high initial phosphate concentrations ( $\mathrm{Li}$ and Stanforth, 2000). Phosphate exists as $\mathrm{HPO}_{4}^{2-}$ during the adsorption process because the $\mathrm{pH}$ of this experimental system is 8 . The $\mathrm{Ca}^{2+}$ concentration of artificial seawater with salinity 5 used in the experiment is $0.00143 \mathrm{M}$ and the solubility product constant $K_{\mathrm{sp}}$ of $\mathrm{CaHPO}_{4}$ is $1 \times 10^{-7}$ at a temperature of $25^{\circ} \mathrm{C}$. Therefore, when the initial phosphate concentration of the solution is $12 \mathrm{mg} \mathrm{L}^{-1}$, the ion product of $\mathrm{HPO}_{4}^{2-}$ and $\mathrm{Ca}^{2+}$ can be calculated as follows:

$$
\begin{aligned}
K & =\left[\mathrm{Ca}^{2+}\right]\left[\mathrm{HPO}_{4}^{2-}\right]=0.00143 \times 12 \times \% 0.001 / 31 \\
& =5.5 \times 10^{-7}>K_{\text {sp }}=1 \times 10^{-7} .
\end{aligned}
$$

The result shows that the condition for precipitation of $\mathrm{CaHPO}_{4}$ is satisfied, which means that $\mathrm{CaHPO}_{4}$ can precipitate on the surfaces of sediments $\mathrm{B}$ and $\mathrm{F}$ and results in 
Table 3. Comparison of the buffering capacity of different sediments to phosphate.

\begin{tabular}{lrrr}
\hline $\begin{array}{l}\text { Sediment } \\
\text { samples }\end{array}$ & $\begin{array}{r}\mathrm{EPC}_{0} \\
\left(\mathrm{mg} \mathrm{L}^{-1}\right)\end{array}$ & $\begin{array}{r}K \\
\left(\mathrm{Lg}^{-1}\right)\end{array}$ & $\begin{array}{r}\mathrm{Ps}_{\left(\mu P C_{0}\right.} \\
\left(\mu \mathrm{Pg}^{-1}\right)\end{array}$ \\
\hline A & 0.061 & 0.314 & 19.185 \\
$\mathrm{~B}$ & 0.014 & 0.177 & 2.490 \\
$\mathrm{~F}$ & 0.029 & 0.220 & 6.304 \\
$\mathrm{Z4}$ & 0.057 & 0.562 & 32.164 \\
\hline
\end{tabular}

$\mathrm{EPC}_{0}$ : Zero equilibrium phosphate concentration; $K$ : Linear adsorption coefficient; Ps_EPC $_{0}$ : Equilibrium-adsorbed phosphate.

an increase in apparent $\mathrm{P}$-adsorption capacity in these samples. This may also explain why the P-adsorption data of these samples are well described by the exponential equations. Note that the adsorption isotherms of samples A, Z4 and $\mathrm{W} 4$ do not show the same distinctive increase of Padsorption capacity when the initial liquid-phase phosphate concentration is higher than $12 \mathrm{mg} \mathrm{L}^{-1}$ (Fig. 2a). The following factors help to explain these different behaviors. First, as shown in Table 1, the percentage of the particles smaller than $0.005 \mathrm{~mm}$ in samples $\mathrm{B}$ and $\mathrm{F}$ is only $5-6 \%$, which is much lower than that in samples A, Z4 and W4 (20-28\%). This means that particles in samples A, Z4 and W4 are likely to have higher specific surface areas than those in samples B and F. Second, from Table 2, the P binding energy constants (b) calculated using the Langmuir equation for samples A, Z4 and W4 (0.346-0.428) are much higher than those for samples B and F (0.064-0.181). The constant $b$ represents the binding capacity of the sediment surface for phosphate. This means that when the ion product of $\mathrm{HPO}_{4}^{2-}$ and $\mathrm{Ca}^{2+}$ in the experimental system is saturated, the adsorption reaction continues to dominate in samples A, Z4 and W4 because of the high specific surface areas and strong P-binding capacities of these sediments (Özacar, 2003).

\subsection{Buffering effects}

The results of buffering adsorption experiments are shown in Fig. 3. At low initial $\mathrm{P}$ concentrations, the adsorption curve crosses the $x$-axis, where $\Delta \mathrm{P}_{\mathrm{S}}$ is 0 . This indicates the point at which there is no net $\mathrm{P}$ exchange between sediment and the incubation solution. The concentration of $\mathrm{P}$ in the equilibrium solution at $\Delta \mathrm{P}_{\mathrm{S}}=0$ is termed the "zero equilibrium phosphate concentration $\left(\mathrm{EPC}_{0}\right)$ " and represents the concentration at which the sediments typically display their maximum buffering capacities to changes in solution $\mathrm{P}$ (Bridgham et al., 2001). The $\mathrm{EPC}_{0}$ value is traditionally considered as the soluble $\mathrm{P}$ concentration for natural systems in long-term equilibrium.

The slope of the adsorption curve at $\Delta \mathrm{P}_{\mathrm{S}}=0$ is the linear adsorption coefficient $(K)$, which indicates the sediment's buffering intensity at $\mathrm{EPC}_{0}$ (and also the maximum
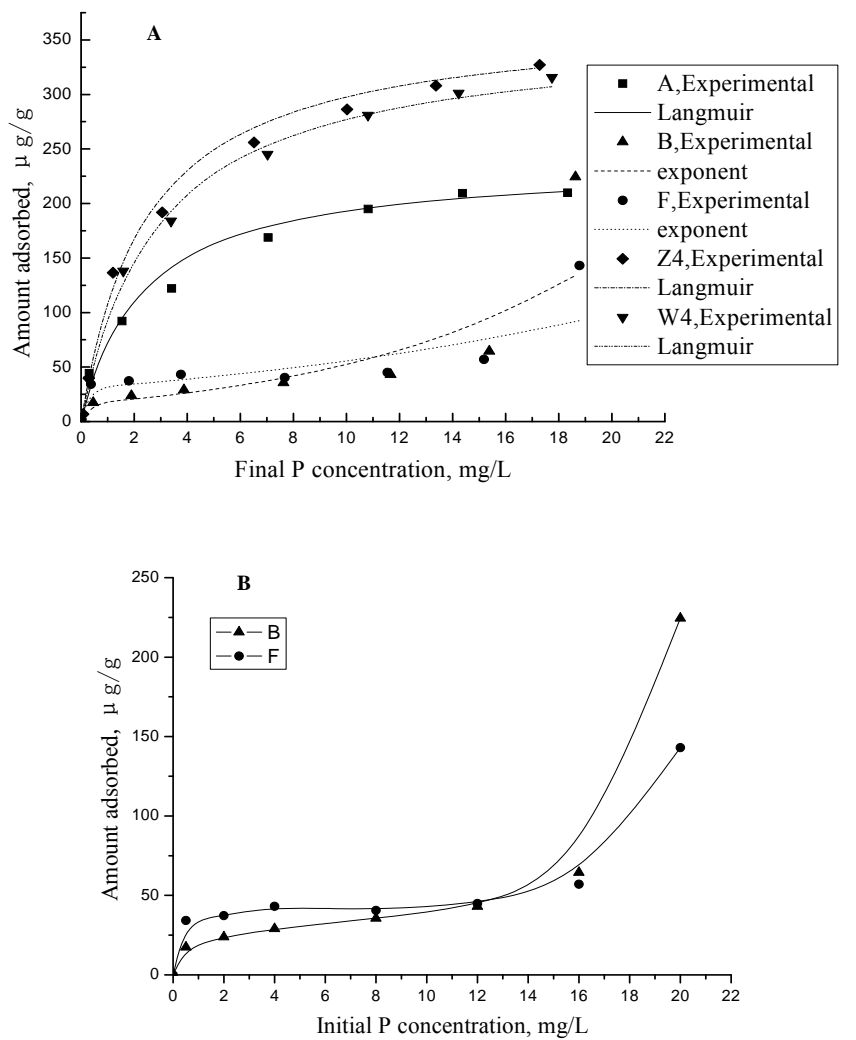

Fig. 2. (a) Adsorption isotherms of different sediments; (b) Adsorption capacity vs. initial liquid-phase phosphate concentrations of samples B and F.

buffering intensity for certain sediments). The $\mathrm{P}$ adsorbed to sediment at $\mathrm{EPC}_{0}$ is called the equilibrium-adsorbed phosphate $\left(\mathrm{Ps}_{\mathrm{SPC}} \mathrm{EPC}_{0}\right)$ and is a measure of the mass of reactive phosphate carried on per gram of sediment that is available for release to a solution devoid of phosphate. $\mathrm{Ps} \_$EPC $_{0}$ can be calculated by

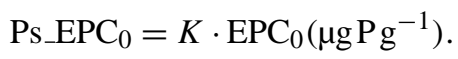

The values of $\mathrm{EPC}_{0}, K$ and Ps $\mathrm{EPC}_{0}$ (Table 3 ) for four sediment samples used in this study were obtained from the buffering adsorption data. The $\mathrm{EPC}_{0}$ values ranged from 0.014 to $0.061 \mathrm{mg} \mathrm{L}^{-1}$. The maximum $\mathrm{EPC}_{0}$ was found in sample $\mathrm{A}\left(0.061 \mathrm{mg} \mathrm{L}^{-1}\right)$, although the $\mathrm{EPC}_{0}$ value for sample Z4 was similar $\left(0.057 \mathrm{mg} \mathrm{L}^{-1}\right)$. The $\mathrm{EPC}_{0}$ values for samples B and $\mathrm{F}$ were relatively low (0.014 and $0.029 \mathrm{mg} \mathrm{L}^{-1}$, respectively). Similar patterns were observed for $K$ values, which ranged between 0.177 and $0.562 \mathrm{Lg}^{-1}$. The highest $K$ value $\left(0.562 \mathrm{Lg}^{-1}\right)$ was observed in sample $\mathrm{Z} 4$, which also had the highest $\mathrm{Ps}_{-} \mathrm{EPC}_{0}$ value $(32.164 \mu \mathrm{g}$ $\left.\mathrm{Pg}^{-1}\right)$. Sediment A also had a relatively high $\mathrm{Ps}_{-} \mathrm{EPC}_{0}$ value $\left(19.185 \mu \mathrm{g} \mathrm{P} \mathrm{g}^{-1}\right)$. One possible explanation for the higher $K$ and $\mathrm{Ps}_{-} \mathrm{EPC}_{0}$ values derived for samples $\mathrm{A}$ and $\mathrm{Z} 4$ compared to those of sediments $\mathrm{B}$ and $\mathrm{F}$ is the higher content of fine particles $(<0.005 \mathrm{~mm})$ and organic matter in these sediments 


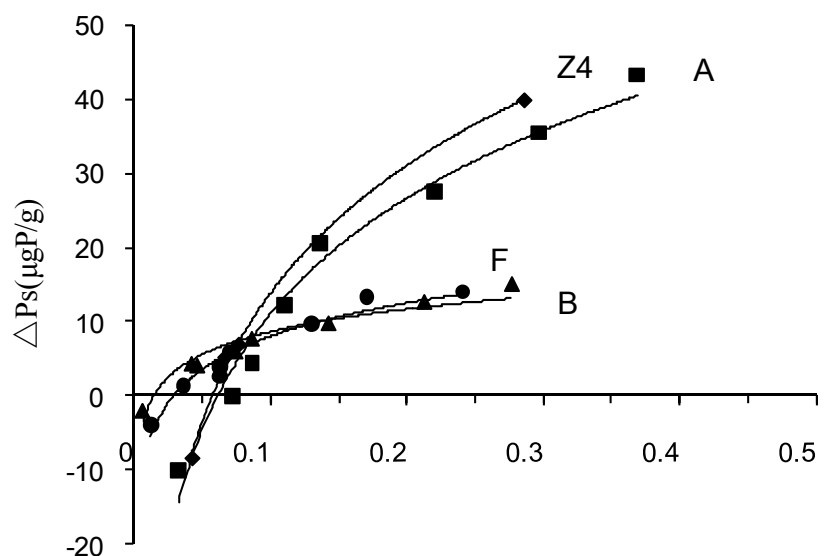

Equilibrium P concentration (mg/L)

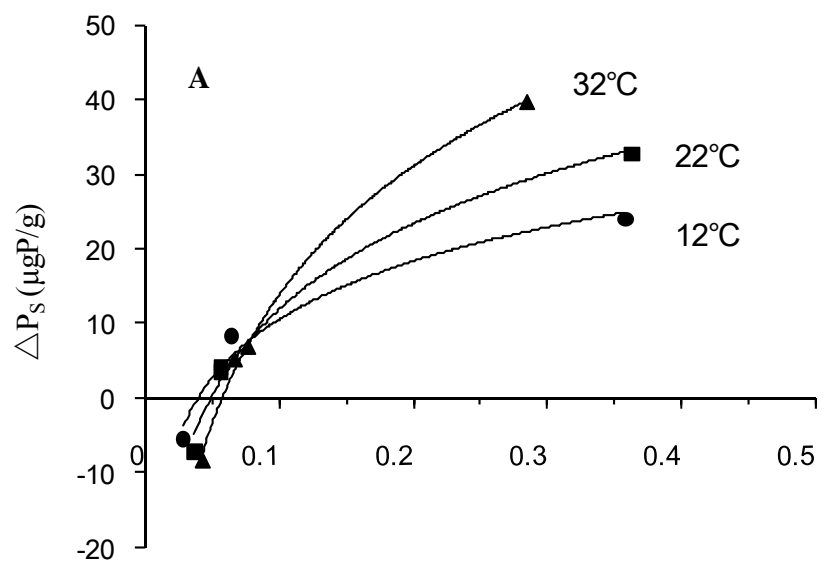

Equilibrium P concentration ( $\mathrm{mg} / \mathrm{L})$
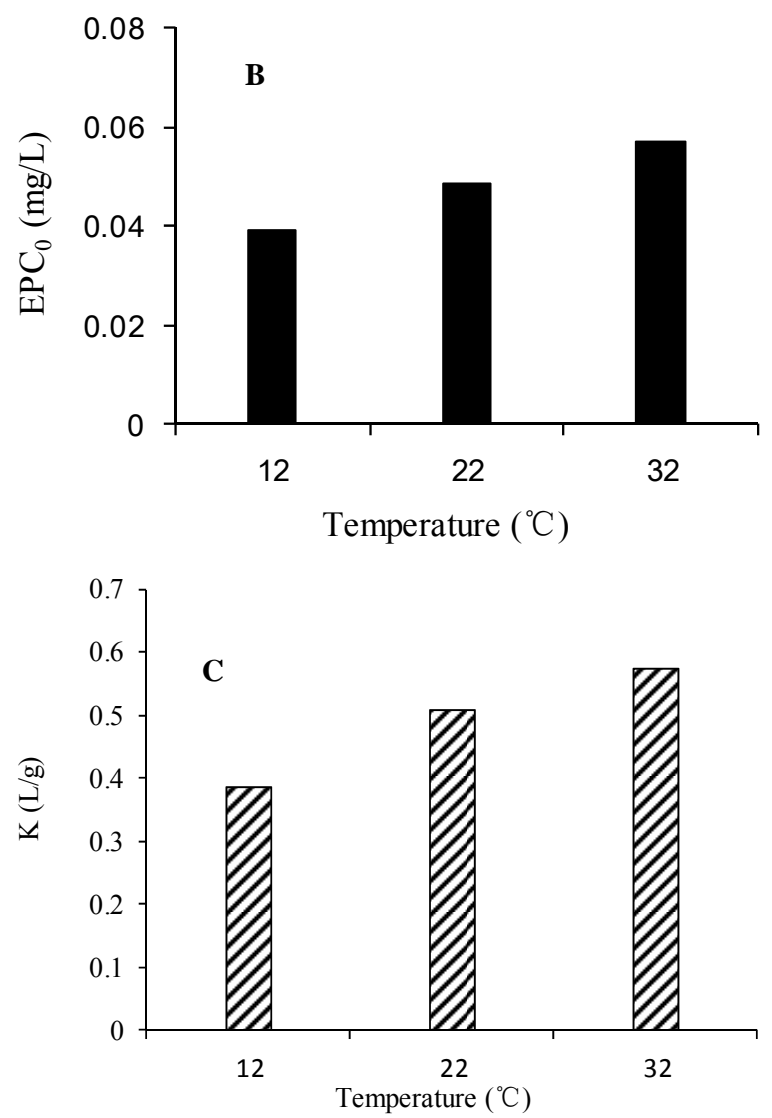

Fig. 4. Relationship between equilibrium solution $P$ concentration $\left(\mathrm{mg} \mathrm{L}^{-1}\right)$ and the amounts of adsorbed or desorbed $\mathrm{P}\left(\mu \mathrm{g} \mathrm{Pg}^{-1}\right)$ under different temperatures for sediment sample Z4 (a). Changes of $\mathrm{EPC}_{0}$ (b) and $K$ (c) with temperatures for sediment sample $\mathrm{Z} 4$.

As the temperature $(T)$ increases, values of $\mathrm{EPC}_{0}$ and $K$ also increase (due to a shift in the sorption isotherm). However, the slope of the regression line for $\mathrm{EPC}_{0}$ is not significant. Increasing the temperature from $12{ }^{\circ} \mathrm{C}$ to $32^{\circ} \mathrm{C}$ resulted in an increase in $\mathrm{EPC}_{0}$ for sediment $\mathrm{Z} 4$ from 0.04 to $0.06 \mathrm{mg} \mathrm{L}^{-1}$, which was similar to the observed 
concentration of soluble reactive phosphate in seawater near the Zhuyuan outfall. The value of $K$ also increases with temperature, suggesting that buffering capability of sediment for phosphate is enhanced as the temperature increases. The rate of both adsorption and desorption will increase with temperature. Thus, as well as shifting the equilibrium ratio between sorbed and dissolved phase $\mathrm{P}$ concentrations, the response time to changes in $\mathrm{P}$ availability will reduce at higher temperatures.

Most red tide algae tend to grow quickly at high temperatures (Dae-Il et al., 2004). For example, Yamaguchi et al. (2010) reported that Chattonella ovata could grow rapidly at temperatures over $20^{\circ} \mathrm{C}$ and that maximal growth rates were between 25 and $30^{\circ} \mathrm{C}$. Our finding of increased $\mathrm{P}$ buffering capacity at high temperatures might be an explanation for this phenomenon.

\section{Conclusions}

- P sorption in sediments with a high fraction of fine particles was best described using the Langmuir equation. Sorption of $\mathrm{P}$ in sediments with a low fraction of fine particles was best described using an exponential sorption equation.

- The precipitation reaction of $\mathrm{CaHPO}_{4}$ from $\mathrm{Ca}^{2+}$ and $\mathrm{HPO}_{4}^{2-}$ occurs in parallel with the sorption process in some samples when the dissolved phosphate concentration is higher than $12 \mathrm{mg} \mathrm{L}^{-1}$. The increase in apparent $\mathrm{P}$-sorption capacities at high initial $\mathrm{P}$ concentrations in these samples may be caused by this precipitation reaction and may explain why the sorption data were best described using an exponential model.

- The $\mathrm{EPC}_{0}$ values derived from the buffer experiments ranged between 0.014 and $0.061 \mathrm{mg} \mathrm{L}^{-1}$. These concentrations are consistent with measured phosphate concentrations in water samples collected from the Yangtze Estuary and Hangzhou Bay. They reveal a potential for predicting the dissolved $\mathrm{P}$ concentration using a sediment buffer experiment.

- The $K$ values vary from 0.177 to $0.562 \mathrm{Lg}^{-1}$ and increase with increasing fine particle and organic matter content. It is suggested that sediments which are rich in fine particles and organic matter have stronger buffering capacities for phosphate.

- Values of sediment $\mathrm{EPC}_{0}$ and $K$ all increase with increasing temperature. This may provide one explanation for why "red tides" tend to occur in warm weather, due to higher $\mathrm{P}$ buffering capacity at high temperatures.

Acknowledgements. This work was supported by "the Fundamental Research Funds for the Central Universities" (no. YX 2010-28), the
National Natural Science Foundation of China (no. 51279004, no. 50709001) and the Natural Science Foundation of Beijing, China (no. 8083029). Li was also supported by the State Scholarship Fund of China (No. 2009651510) to pursue her research at Cranfield University as a visiting scholar from August 2010 to August 2011.

Edited by: S. Pantoja

\section{References}

Bao, S. D. and Jiang, R. F.: Measurement of organic matter content in soil, in: Analysis of Agri-Chemistry in Soil, 3rd Edn., Chinese Agricultural Science and Technology Press, Beijing, China, 1999.

Beuselinck, L., Govers, G., Poesen, J., Degraer, G., and Froyen, L.: Grain-size analysis by laser diffractometry: comparison with the sieve-pipette method, CATENA, 32, 193-208, doi:0.1016/s03418162(98)00051-4, 1998.

Borggaard, O. K., Szilas, C., Gimsing, A. L., and Rasmussen, L. H.: Estimation of soil phosphate adsorption capacity by means of a pedotransfer function, Geoderma, 118, 55-61, doi:10.1016/s0016-7061(03)00183-6, 2004.

Bridgham, S. D., Johnston, C. A., Schubauer-Berigan, J. P., and Weishampel, P.: Phosphorus sorption dynamics in soils and coupling with surface and pore water in riverine wetlands, Soil Sci. Soc. Am. J., 65, 577-588, 2001.

Conley, D. J., Smith, W. M., Cornwell, J. C., and Fisher, T. R.: Transformation of particle-bound phosphorus at the land-sea interface, Estuarine, Coast. Shelf Sci., 40, 161-176, 1995.

Dae-Il, K., Yukihiko, M., Sou, N., Mineo, Y., Yang-Ho, Y., Yuji, O., Nobuyoshi, I., and Tsuneo, H.: Effects of temperature, salinity and irradiance on the growth of the harmful red tide dinoflagellate Cochlodinium polykrikoides Margalef (Dinophyceae), J. Plankton Res., 26, 61-66, 2004.

de Assis, C. P., de Oliveira, T. S., da Nóbrega Dantas, J. d. A., and de Sá Mendonça, E.: Organic matter and phosphorus fractions in irrigated agroecosystems in a semi-arid region of Northeastern Brazil, Ag. Ecosys. Environ., 138, 74-82, doi:10.1016/j.agee.2010.04.002, 2010.

Froelich, P. N.: Kinetic control of dissolved phosphate in natural rivers and estuaries: A primer on the phosphate buffer mechanism, Limnol. Oceanogr., 33, 649-668, 1988.

Kara, D., Özsavasçi, C., and Alkan, M.: Investigation of suitable digestion methods for the determination of total phosphorus in soils, Talanta, 44, 2027-2032, doi:10.1016/s00399140(97)00014-3, 1997.

Kawasaki, N., Ogata, F., and Tominaga, H.: Selective adsorption behavior of phosphate onto aluminum hydroxide gel, J. Hazard. Mater., 181, 574-579, doi:10.1016/j.jhazmat.2010.05.051, 2010.

Krol, M. S. and Bronstert, A.: Regional integrated modelling of climate change impacts on natural resources and resource usage in semi-arid Northeast Brazil, Environ. Modell. Software, 22, 259268, 2007.

Liu, J. P. and Sgluo, G.: Chemistry oceanography, 2nd Edn., Ocean Press, Beijing, China, 1982.

Li, L. and Stanforth, R.: Distinguishing adsorption and surface precipitation of phosphate on goethite $(\alpha-\mathrm{FeOOH})$, J. Colloid Inter. Sci., 230, 12-21, 2000. 
Li, M., Wei, H. P., Wang, G. Q., and Ni, J. R.: Study on adsorption behavior of phosphate by sediments from Changjiang estuary and Hangzhou bay, Acta Oceanol. Sinica, 26, 132-136, 2004 (in Chinese).

Ohno, T., Griffin, T. S., Liebman, M., and Porter, G. A.: Chemical characterization of soil phosphorus and organic matter in different cropping systems in Maine, USA, Agr. Ecosys. Environ., 105, 625-634, doi:10.1016/j.agee.2004.08.001, 2005.

Özacar, M.: Adsorption of phosphate from aqueous solution onto alunite, Chemosphere, 51, 321-327, doi:10.1016/s00456535(02)00847-0, 2003.

Pratt, C. and Shilton, A.: Suitability of adsorption isotherms for predicting the retention capacity of active slag filters removing phosphorus from wastewater, Water Sci. Technol., 59, 1673-1678, 2009.

Price, R. M., Savabi, M. R., Jolicoeur, J. L., and Roy, S.: Adsorption and desorption of phosphate on limestone in experiments simulating seawater intrusion, Applied Geochemistry, 25, 1085-1091, doi:10.1016/j.apgeochem.2010.04.013, 2010.
Richardson, C. J.: Mechanisms controlling phosphorus retention capacity in freshwater wetlands, Science, 228, 1424-1427, 1985.

Schippers, P., van de Weerd, H., de Klein, J., de Jong, B., and Scheffer, M.: Impacts of agricultural phosphorus use in catchments on shallow lake water quality: About buffers, time delays and equilibria, Sci. Total Environ., 369, 280-294, doi:10.1016/j.scitotenv.2006.04.028, 2006.

Wauchope, R. D. and McDowell, L. L.: Adsorption of phosphate, arsenate, methanearsonate, and cacodylate by lake and stream sediments: Comparisons with soils, J. Environ. Qual., 13, 499504, 1984.

Xiang, S. L. and Zhou, W. B.: Phosphorus forms and distribution in the sediments of Poyang Lake, China, Int. J. Sedim. Res., 26, 230-238, 2011.

Yamaguchi, H., Mizushima, K., Sakamoto, S., and Yamaguchi, M.: Effects of temperature, salinity and irradiance on growth of the novel red tide flagellate Chattonella ovata (Raphidophyceae), Harmful Algae, 9, 398-401, doi:10.1016/j.hal.2010.02.001, 2010 . 